\title{
Article \\ Chloride Penetration Behavior of Concrete Made from Various Types of Recycled Concrete Aggregate
}

\author{
Wanchai Yodsudjai and Kirati Nitichote *
}

check for

updates

Citation: Yodsudjai, W.; Nitichote, K. Chloride Penetration Behavior of Concrete Made from Various Types of Recycled Concrete Aggregate. Sustainability 2022, 14, 2768. https://doi.org/10.3390/su14052768

Academic Editors: Carlos Morón Fernández and Daniel

Ferrández Vega

Received: 27 January 2022

Accepted: 22 February 2022

Published: 26 February 2022

Publisher's Note: MDPI stays neutral with regard to jurisdictional claims in published maps and institutional affiliations.

Copyright: (c) 2022 by the authors Licensee MDPI, Basel, Switzerland. This article is an open access article distributed under the terms and conditions of the Creative Commons Attribution (CC BY) license (https:// creativecommons.org/licenses/by/ $4.0 /)$.
Department of Civil Engineering, Kasetsart University, Bangkok 10900, Thailand; fengwcy@ku.ac.th * Correspondence: kirati.ni@ku.th

\begin{abstract}
This research aimed to identify the link between the chloride penetration behavior of concrete made from various types of recycled aggregate from three main sources-building demolition waste (B-RCA), laboratory waste (L-RCA), and precast concrete waste (P-RCA) — and the 28-days compressive strength of natural aggregate concrete with the replacement ration $30 \%, 60 \%$ and $100 \%$ respectively. The results of the study revealed that the quality of recycled aggregate waste significantly impacted concrete behavior. To elaborate, finer aggregate potentially increased the inter-facial transition zone (ITZ), which is the weakness part of concrete, resulting in the concrete having less compressive strength as well as increasing amount of chloride ion penetration thought rapid test. In this research, an image processing technique, which is a simple method, was used to quantify the ITZ area of concrete. It was found that concrete with low compressive strength and high permeability values had an ITZ area significantly more than other types of concrete.
\end{abstract}

Keywords: construction demolition waste; recycle concrete aggregate; sustainable construction

\section{Introduction}

The urban expansion leads to the rise of building construction, especially in developing countries. Therefore, the use of concrete which is the primary material in such construction is also increasing [1]. This results in an increase in the use of natural crushed stone which constitutes two-thirds of the total weight of concrete. Moreover, 5-10 percent of the concrete used in construction has turned into waste [2]. However, the inappropriate disposal of leftover concrete such as dumping it at a landfill and using it in the landfilling process has been widely practiced. This leads to more problems in the future. To tackle the problem, the concept of turning the leftover into aggregate used in concrete is developed.

The sources of aggregate waste from the construction industry come from three main sources: building demolition waste, laboratory waste, and precast concrete waste. [3] The behavior of recycled aggregate concrete differs from that of natural aggregate concrete $[4,5]$ in terms of compressive strength, the efficiency of fresh concrete, chloride penetration, etc. The concrete properties have been tested over and over; however, there has been no explanation of how concrete behavior from various sources is linked to its actual behavior.

This research aimed to analyze the behavior of concrete made from various types of recycled aggregate from different sources in terms of compressive strength and chloride penetration through an image processing technique.

\subsection{Chloride Penetration Behavior}

The longer the concrete is in use, the higher the probability of water and air penetrating it becomes. Ref. [6] The presence of water and air is the cause of other undesirable compounds $[7,8]$. For example, chloride in the water might be found in the concrete. The most undesirable effect of chloride is that it can react with passive film covering the reinforcement, resulting in the passive film deteriorating. As a result, the reinforcement without the passive film will react with the penetrating water and air and will eventually rust. This 
in turn makes the reinforcement occupy a greater volume of the concrete, allowing more air and water to penetrate the concrete. This process, as a chain reaction, accelerates the deterioration of the concrete and reinforcement. [9-11]

According to the EN 1744-1 [12] Test for Chemical Properties of Aggregate, ASTM C33 [13] Standard Specification for Concrete Aggregate, the amount of chloride in natural aggregate must be less than 0.01 percent and can be up to $0.03-0.15$ percent in recycled aggregate by wet chemistry method. This is because chloride content might be present in mortar waste in recycled aggregate or the recycled aggregate itself was previously used where chloride content was present [14]. This results in the increase in water absorption of the concrete corresponding with the amount of the recycled aggregate. This also applies to the chloride penetration ratio of the concrete. According to previous studies, [15] the problem of chloride penetration behavior could be solved by decreasing the water over cement ratio. This would help the concrete yield the desirable strength. Moreover, the research conducted by [16] found that the type of recycled aggregate also plays a role in the chloride penetration behavior of concrete, with the chloride penetration of fine aggregate higher than that of coarse aggregate.

\subsection{Sources of Recycled Aggregate}

There have been studies on recycled aggregate in concrete for some time. Reliable studies mentioned the properties of concrete and the behavior of the construction from recycled aggregate concrete. They found that recycled aggregate concrete plays a significant role in water absorption in aggregate, leading to lowered permeability resistance [17]. The water absorption capacity of recycled aggregate concrete is considered high ( $>7$ percent) according to the standardized measure provided by [18] JIS A5002. Moreover, recycled aggregate concrete has a lower compressive strength compared to natural aggregate concrete by 21 percent [19]. However, if the amount of recycled aggregate in the concrete is restricted to not more than 20-30 percent of the total concrete, there is a negligible difference between the properties of recycled aggregate concrete and those of natural aggregate concrete. [20] In 2014, [21] Duan and Poon conducted research on the properties of concrete with mortar on the stone surface and from different sources. The result was that recycled aggregate with a little amount of mortar on the stone surface had low water absorption capacity and therefore can be a substitute for natural aggregate. Likewise, the research by [22] Pedro et al., 2014 also found that the water absorption capacity of recycled aggregate was medium as represented by 3.9-7.6 percent. As a result, a recycled aggregate could be used in concrete with high compressive strength.

Still, the aforementioned research did not analyze the cause of different behaviors of three different types of aggregate concrete. Also, it is worth mentioning that the research did not take the recycled aggregate which came from different sources into account. More importantly, the area of ITZ which significantly affects the properties of the concrete was not considered.

\section{Materials and Methods}

The recycled aggregate made from 3 sources was investigated (Figure 1). The first was the leftover cube concrete specimens from laboratory testing, with an existing strength ranging from 40-45 $\mathrm{MPa}$. The second was the waste from the rejected product from the precast hollow core slab industry with an average strength of $35 \mathrm{Mpa}$. The last one was the building demolition waste, especially the building demolition concrete from the building of which the location interposes the new underground MRT Orange line in the capital city of Thailand. This example emphasizes the increasing demand for infrastructure renovation from the fast-growing city. The coring sample of concrete structure from the building was tested to verify its existing compressive strength which turned out to be $16 \mathrm{Mpa}$ on average. B-RA, P-RA, and L-RA represent recycled aggregate from building demolition, aggregate from precast concrete waste, and aggregate from laboratory waste respectively. The concrete waste was crushed and graded according to ACI 555 [23]. Then, 
the natural aggregate concrete was replaced by L-RCA, P-RCA, B-RCA with the proportion of 30 percent, 60 percent, and 100 percent respectively as indicated in Table 1 . Short-Term properties of concrete from recycled aggregate were verified in terms of strength and elastic modulus in the period of 7,14, and 28 days. The durability of the concrete was represented by a rapid chloride penetration test (ASTM C 1202) [24] at 28 day-age concrete.
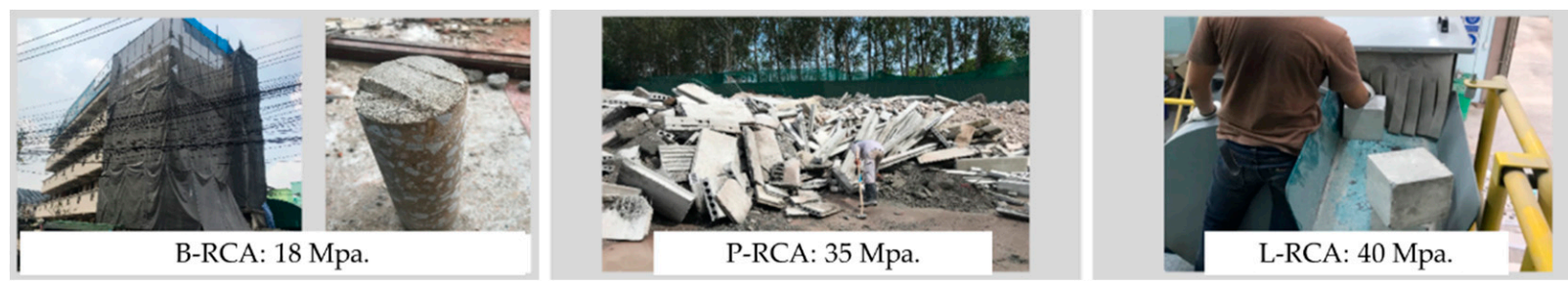

Figure 1. Recycled aggregate from various sources.

Table 1. Mixed proportions of concrete mixture.

\begin{tabular}{cccccc}
\hline \multirow{2}{*}{ Mix } & \multicolumn{5}{c}{ Mix Proportion $\left(\mathbf{k g} / \mathbf{m}^{3}\right)$} \\
\cline { 2 - 6 } & Cement & Water & Sand & Stone & RA \\
\hline NCA & 411 & 206 & 827 & 1028 & - \\
\hline L-RA 30 & 411 & 206 & 827 & 719 & 309 \\
\hline L-RA 60 & 411 & 206 & 827 & 616 & 412 \\
\hline L-RA 100 & 411 & 206 & 827 & - & 1028 \\
\hline P-RA 30 & 411 & 206 & 827 & 719 & 309 \\
\hline P-RA 60 & 411 & 206 & 827 & 616 & 412 \\
\hline P-RA 100 & 411 & 206 & 827 & - & 1028 \\
\hline B-RA 30 & 411 & 206 & 827 & 719 & 309 \\
\hline B-RA 60 & 411 & 206 & 827 & 616 & 412 \\
\hline B-RA 100 & 411 & 206 & 827 & - & 1028 \\
\hline
\end{tabular}

The standard controlled concrete mix ratio for comparison with recycled aggregate concrete was Natural Concrete Aggregate (NCA). The mixing ratio was calculated to obtain the required tensile strength of approximately $25 \mathrm{Mpa}$. Then in the experiment, different proportions of the aggregates from natural stone were substituted. By using aggregate from the recycling as mentioned above. Table 1 shows the proportion of concrete mix used in the sample for this test.

\subsection{Aggregate}

The aggregate used in the concrete mixture was from three sources. From Figure 2, the particles of L-RCA and B-RCA were larger than that of P-RCA due to the smaller size of natural crushed stone used in precast concrete. Another point was that L-RCA possessed less cement paste on the aggregate's surface because of its higher parent strength compared to that of B-RA. The shape of L-RA aggregates is angular, similar to those obtained from natural stone. The B-RA is also angular, but from a comparative physical appearance, it appears to have more porosity from old-adhered mortar. The final aggregates that make up the fraction of Precast Hollow Core Slab are round but small and very porous as well.

According to the test, the distribution of different particle sizes of the coarse aggregate corresponded to ASTM C135 [25] Standard Test Method for Sieve Analysis of Fine and Coarse Aggregates as shown in Figure 3. However, it could be observed that the distribution of precast concrete waste of different sizes with mostly fine aggregate was higher than that of other types of aggregate. 


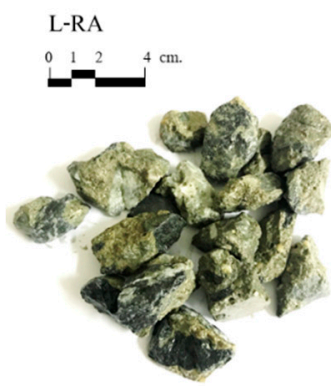

L-RA

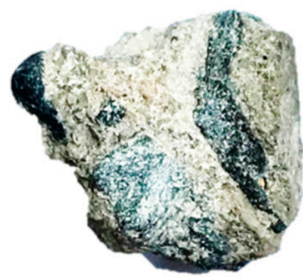

$1 \mathrm{~cm}$.

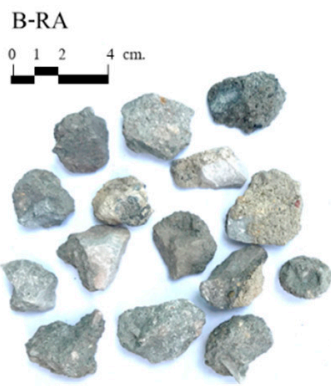

B-RA

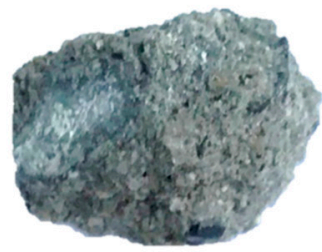

$1 \mathrm{~cm}$.

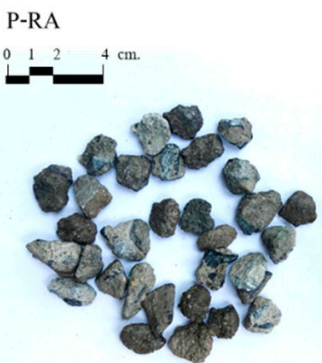

P-RA

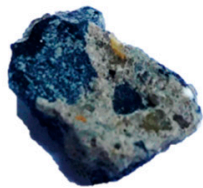

$1 \mathrm{~cm}$.

Figure 2. Recycled aggregate from laboratory waste (L-RA), building demolition waste (B-RA) and precast concrete waste (P-RA).

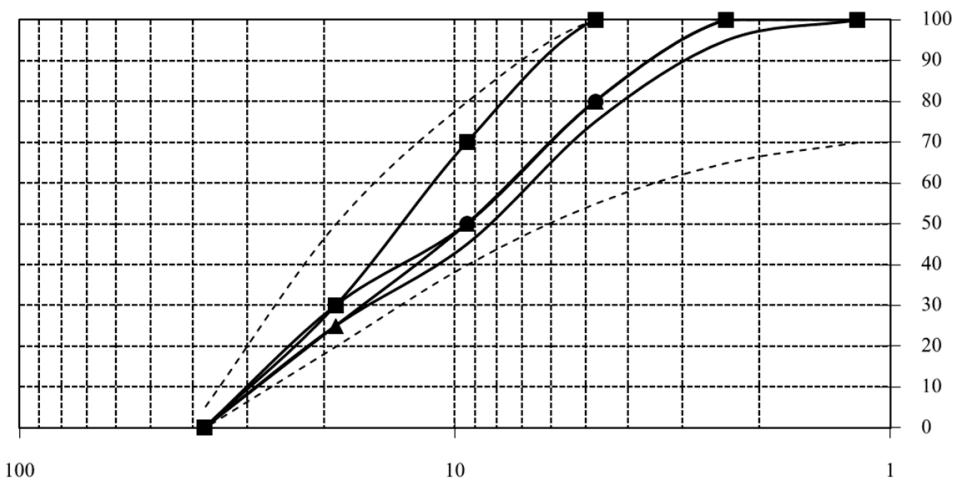

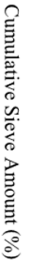

Aggregate Size (mm.)

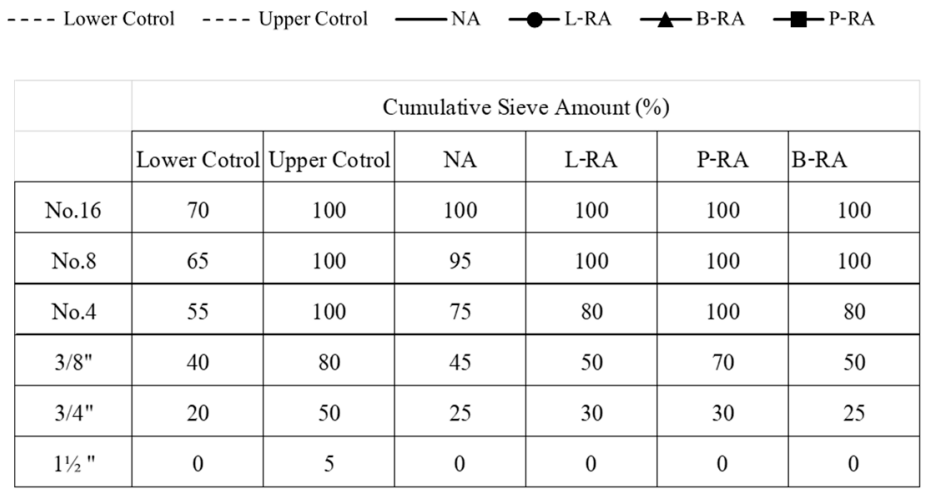

Figure 3. Aggregate particle size distribution.

\subsection{Unit Weight and Absorption Rate of Aggregate}

The unit weight of natural aggregate is a little bit higher than that of recycled aggregate, as represented by $14-19 \%$. From Figure 4, the unit weight of natural aggregate was higher 
than that of every type of recycled aggregate. This was because there was mortar waste on the surface and the crushing process might leave the shape of the surface distorted. Moreover, the particle size of recycled aggregate was mostly at the same size range, resulting in more rooms in concrete and eventually in lower unit weight. Considering the water absorption rate, it was obvious that the unit weight of natural aggregate was lower than that of recycled aggregate. From Figure 5, the water absorption percentage of recycled aggregate was $6.65,8.72$, and 6.78 times higher than that of natural aggregate. This was because there was mortar present on the outer surface of recycled aggregate, resulting in higher porosity, lower specific gravity, and higher water absorption when compared to natural aggregate.

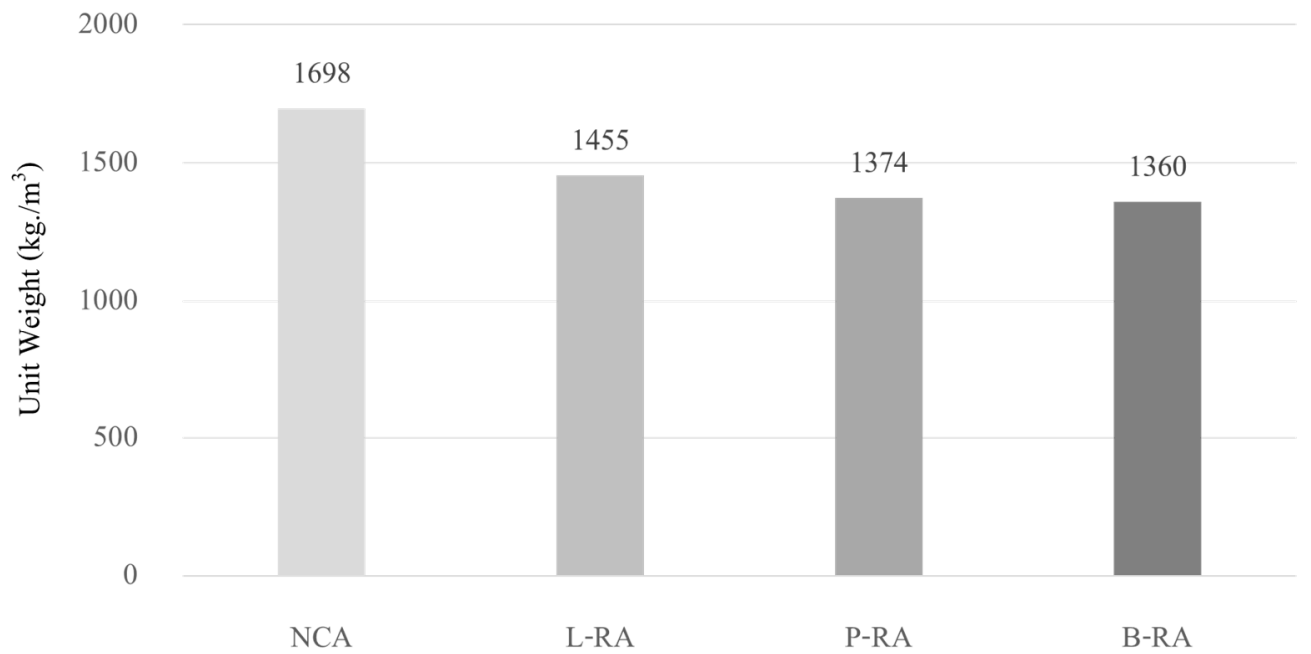

Figure 4. The unit weight of aggregate.

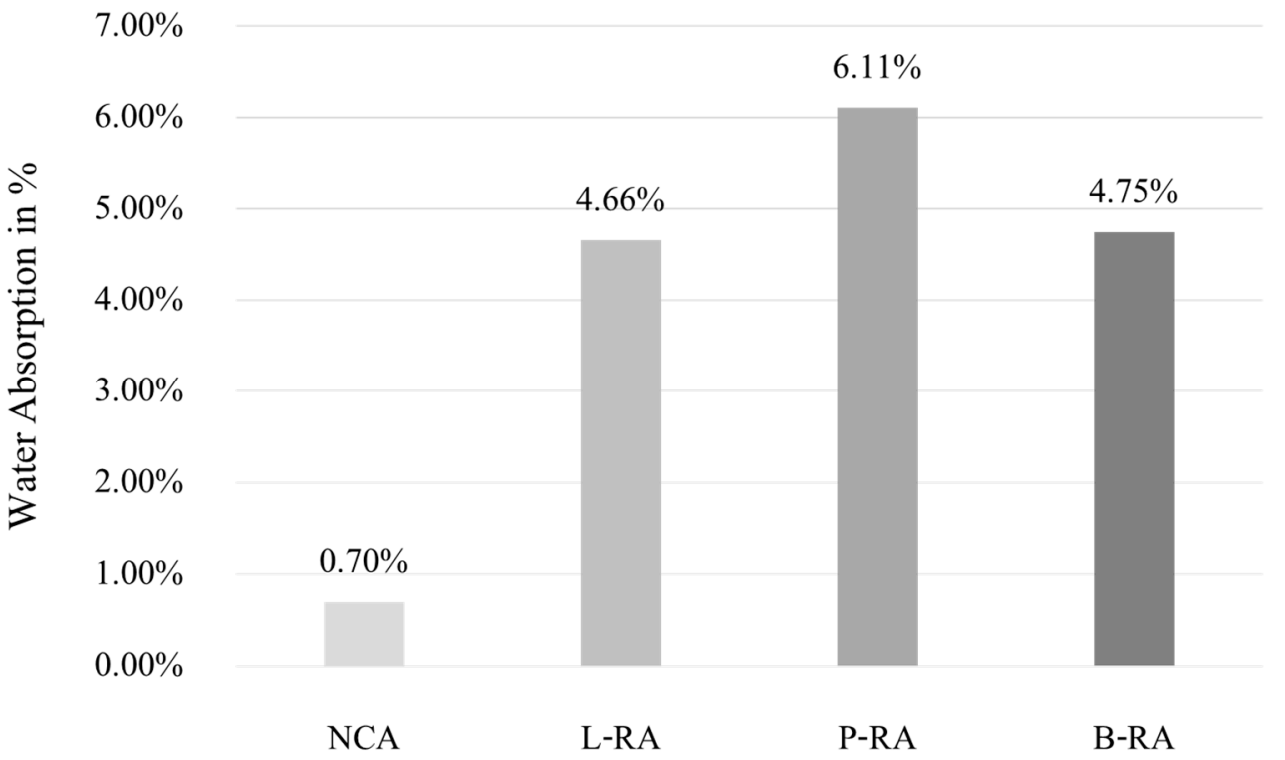

Figure 5. Percentage of Water Absorption for each type of Aggregates.

\subsection{Rapid Chloride Penetration}

The chloride penetration concrete test according to ASTM C 1202 was conducted using a rapid chloride permeability test after a 28-day period of curing. From Figure 6 , the test consisted of a clamp tab, a concrete cube containing a 3 percent concentration of sodium chloride $(\mathrm{NaCl})$ solution on the cathode side and a $0.3 \mathrm{M}$ concentration of sodium 
hydroxide $(\mathrm{NaOH})$ on the anode side. Then, it is connected to a 60-volt DC power supply and data logger.

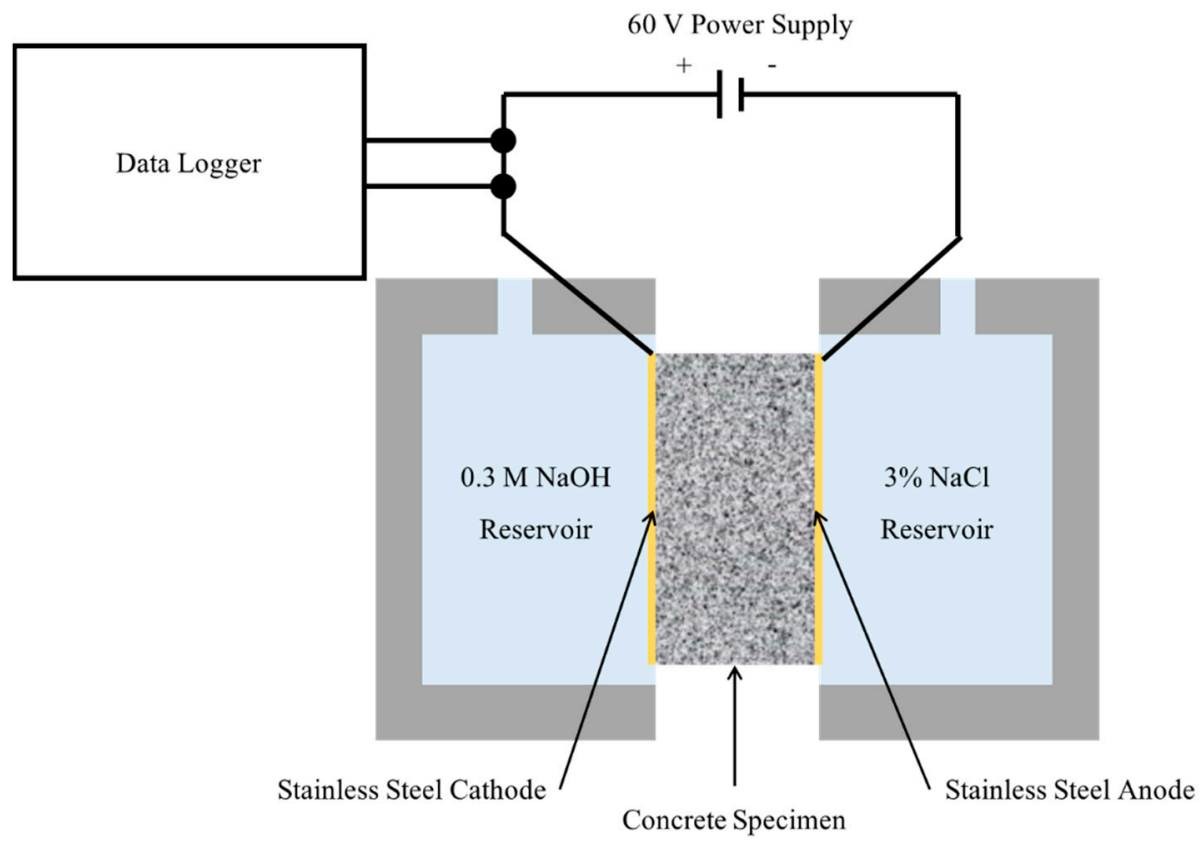

$50 \mathrm{~mm}$. Long, $100 \mathrm{~mm}$. Diameter

Figure 6. Test setup of the Rapid Chloride Penetration Test.

According to the experiment, although the chloride ion permeability, which is an indicator of concrete durability, could not be measured, the total amount of chloride ion permeating through the concrete was measured. Still, the result might not be easily applicable in real-life situations. However, ASTM C1202 presented a table to determine the concrete quality with different chloride ion permeabilities as shown in Table 2.

Table 2. Chloride permeability based on the total charge passed.

\begin{tabular}{cc}
\hline Total Charge Passed (Coulombs) & Chloride Permeability \\
\hline$>4000$ & High \\
\hline $2000-4000$ & Moderate \\
\hline $1000-2000$ & Low \\
\hline $100-1000$ & Very low \\
\hline$<100$ & Negligible \\
\hline
\end{tabular}

\subsection{Image Processing}

Figure 7 shown vertical cross section of concrete sample so that the properties of the concrete could be carefully examined. Then, the concrete was captured with a digital camera with at least $5 \mathrm{MB}$ resolution. The image was then analyzed by the MATLAB program, in which the process involved converting the image to greyscale so that the color intensity of each element in the concrete could be clearly seen. After this process, the image was denoised. Subsequently, the area of ITZ of each element was processed. The result was the differences in color intensity, with the void being the highest, followed by mortar and aggregate respectively. In order to analyze the area of ITZ, the perimeter needed to be identified. Then, the area of ITZ could be determined by multiplying the perimeter by an average ITZ thickness. 


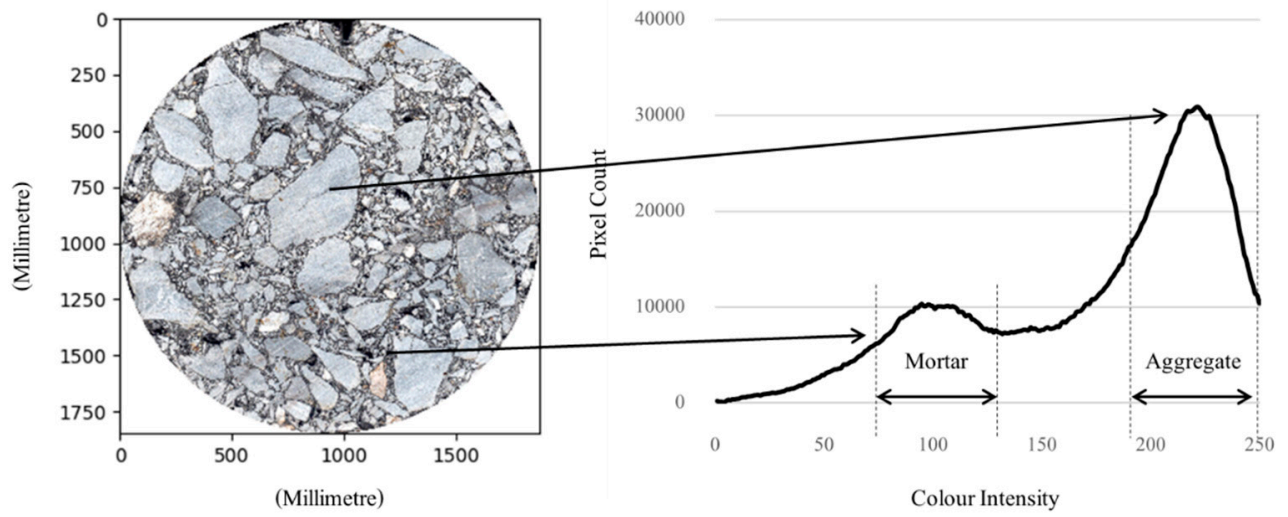

Figure 7. Color pixel population from image processing.

\section{Results}

\subsection{Compressive Strength}

The compressive strength of concrete was tested by using a block of concrete with a compressive strength of $28 \mathrm{MPa}$. Then, each new concrete block was cast from standard cylinder-shaped concrete formworks with a $10 \mathrm{~cm}$. diameter and a $20 \mathrm{~cm}$. in height. After $24 \mathrm{~h}$, the concrete formworks were removed and the concrete blocks were aged in clean water for 7 days, 14 days, and 28 days respectively. The concrete blocks were subsequently tested for compressive strength. Concrete samples with four different coarse aggregates were collected: natural aggregate concrete, laboratory waste concrete (L-RCA), precast concrete waste (P-RCA), and building demolition waste (B-RCA). The natural aggregate concrete was replaced by L-RCA, P-RCA, B-RCA with the proportion of 30 percent, 60 percent, and 100 percent respectively.

From Figure $8 \mathrm{a}-\mathrm{c}$ the decreasing trend in compressive strength corresponded with the increasing amount of recycled aggregate mixed in the concrete. Three types of recycled aggregate concrete with a 30 percent replacement rate showed negligible differences in terms of compressive strength compared to the other two replacement rates. As for the recycled aggregate concrete blocks with a 30 percent replacement rate, the vertical crack propagation occurred, and the cracks split apart into two pieces. This stemmed from the fact that the mortar waste could handle less compressive strength than the coarse aggregate. On the other hand, the coarse aggregate and recycled aggregate themselves did not suffer any damages or cracks. As for the 60 percent replacement rate, the vertical crack propagation occurred and reached half of the concrete's height at a 70-degree angle. The crack resulted from the shear force coming from the bond strength of composite and internal friction. As for the 100 percent replacement rate, the vertical crack propagation occurred and reached one-thirds of the concrete's height, but the crack did not cover all the cross-section concrete areas. Moreover, some of the cracks split into tiny pieces due to the dramatic differences in compressive strength of each recycled aggregate, shear force coming from the bond strength of composite and internal friction. However, their failure tended to be the lowest and could handle the least compressive strength compared to the other two. 
25

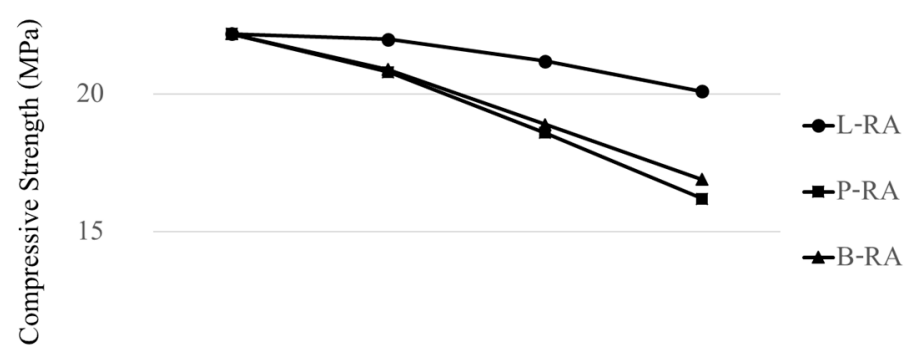

10

$\begin{array}{llll}0 \% & 30 \% & 60 \% & 100 \%\end{array}$

Replacement Rate

(a) Compressive strength at 7 days.

30

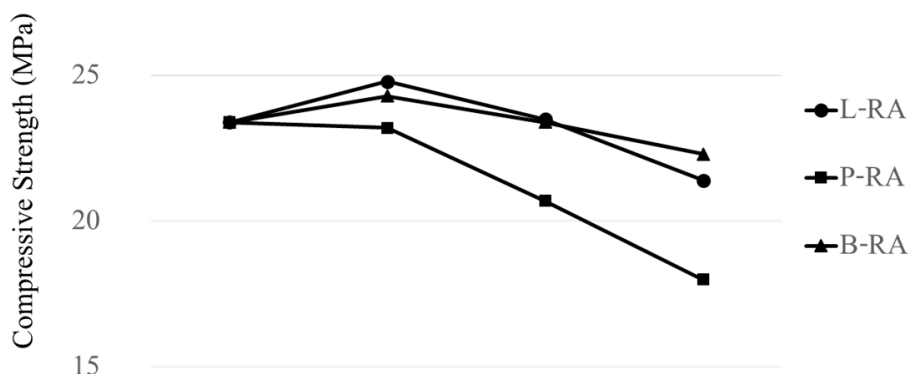

15

$\begin{array}{llll}0 \% & 30 \% & 60 \% & 100 \%\end{array}$

Replacement Rate

(b) Compressive strength at 14 days

35

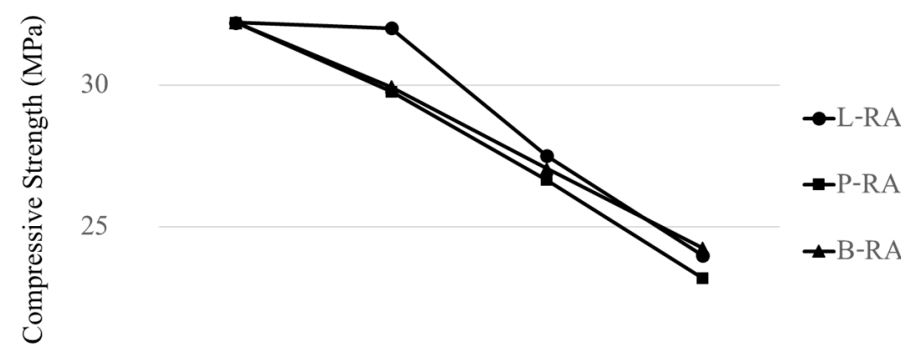

20

$\begin{array}{llll}0 \% & 30 \% & 60 \% & 100 \%\end{array}$

Replacement Rate

(c) Compressive strength at 28 days

Figure 8. Compressive strength of concrete at $0 \%, 30 \%, 60 \%$ and $100 \%$ replacement rate at: (a) 7 days, (b) 14 days, and (c) 21 days. 


\subsection{Chloride Penetration Resistance}

From Figure 9, the result showed total charge passed at 28 days of natural coarse aggregate and various types of recycled aggregate by rapid chloride test. It obviously seen that natural aggregate concrete (NCA) was the only type that had a moderate chloride ion permeability rate (2000-4000 coulombs) in accordance with ASTM C1202. On the other hand, all the proportions of recycled aggregate concrete were considered to have a high chloride ion permeability. Concrete made from laboratory and building demolition aggregate are slightly higher than NCA based value about $25 \%$ at any replacement ratio. There is also an increase in the recycled aggregate to natural aggregate ratio of these two types of samples do not increase the chloride permeability much. It is worth noting that concrete made from scraps of prefabricated concrete slabs. Instead, the permeability value of the chloride is very high. In one way it could be said that at $30 \%$ displacement, the permeability rate is close to that of natural aggregate concrete. But increasing the percentage of renewable aggregates to $60 \%$ or $100 \%$ increased the permeability significantly, over $71 \%$ and $106 \%$ compared to the $30 \%$ recycle aggregate samples, respectively.

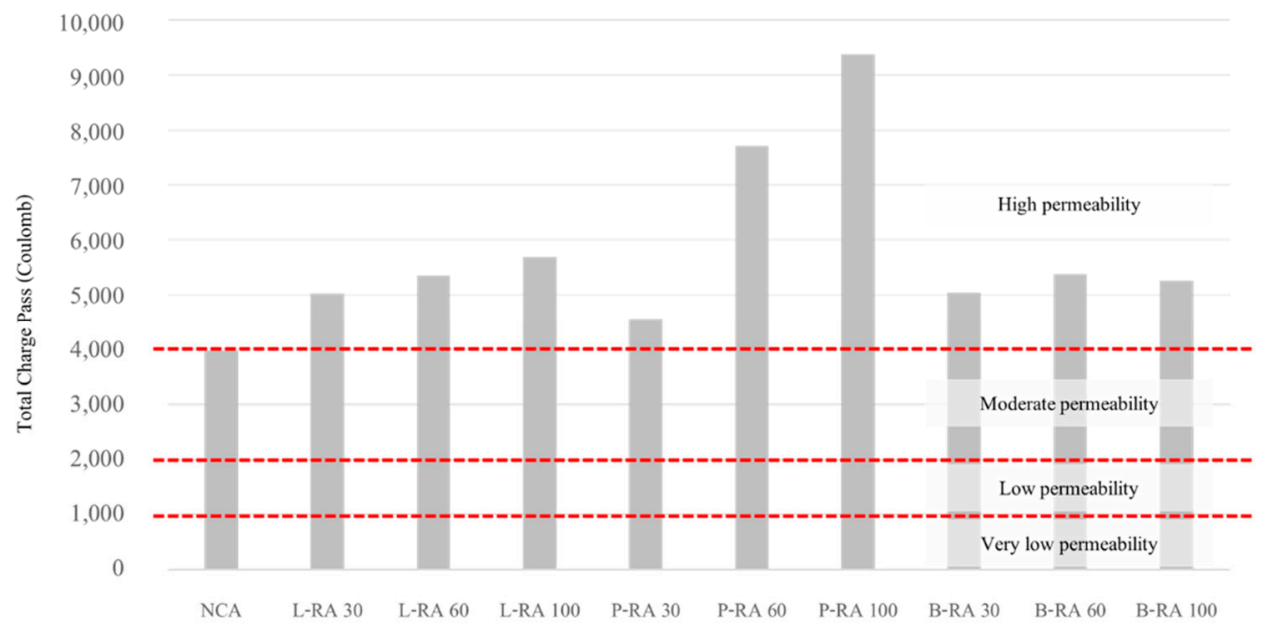

Figure 9. The total charge passed at 28 days of natural coarse aggregate and various types of recycled aggregate.

\subsection{Chloride Penetration and Compressive Strength}

The relationship between chloride penetration and compressive strength of 28-day recycled aggregate concrete is shown in Figure 10. The decreasing penetration rate of L-RCA (Circle), P-RCA (Square), and B-RCA RCA (Triangle) corresponded with their increasing compressive strength. The effect of replacement percentage, it has a high effect on the concrete mixed with P-RCA aggregate when the ratio is increased it will increase the compressive strength and chloride permeability as well. However, for the L-RCA and B-RCA samples, it was found that the increase in the aggregate's substitution ratio had a large effect on the compressive strength and chloride permeability. The two relationships between L-RCA and P-RCA could be explained by $\mathrm{R}^{2}$ which was well fit up to 95 percent and 99 percent respectively. Based on this result, it can be confirmed that linear regression relationship between compressive strength and chloride penetration. However, as for aggregate from the precast slab waste, the chloride penetration rate tended to be very high, which was indirectly proportional to the compressive strength. On the other hand, when considering the water absorption of P-RCA aggregates, it is found that higher water absorption rates than other aggregates have a reliable effect on the absorption values. The passivity of chloride was also higher. This highlighted the sensitivity to a change of compressive strength which significantly affected the porosity of this type of recycled aggregate. 


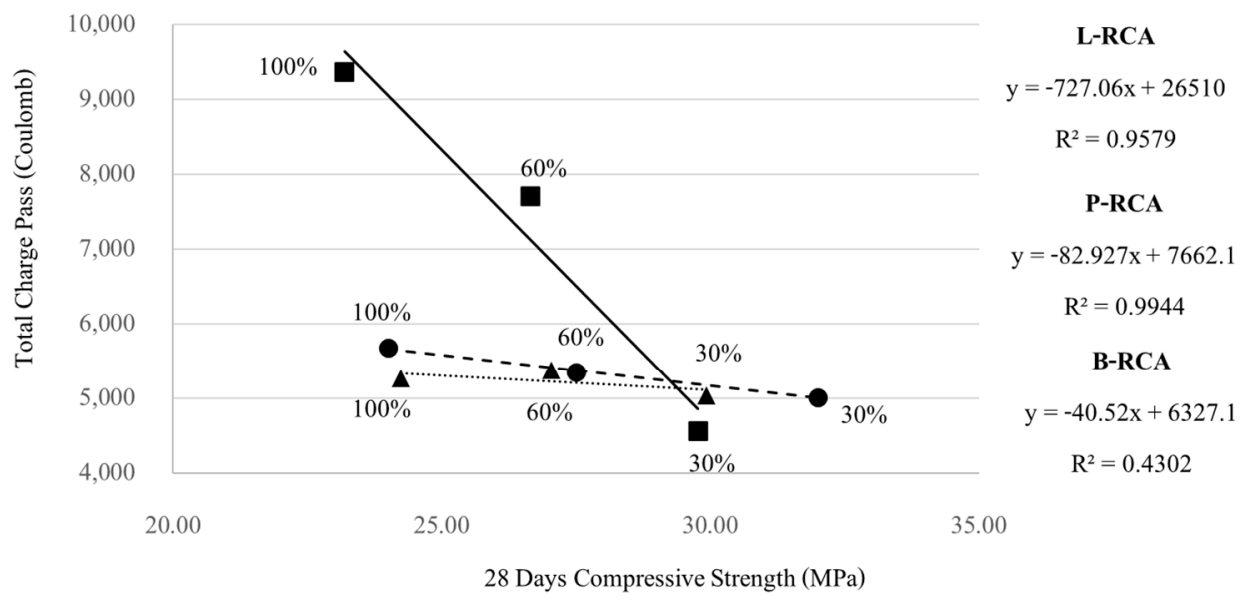

- L-RCA $\square$ P-RCA $\boldsymbol{\Delta}$ B-RCA - - - Linear (L-RCA) — Linear (P-RCA) …….. Linear (B-RCA)

Figure 10. The relationship between the total charge passed and compressive strength.

\section{Discussion}

\subsection{Failure Mode}

The aggregate porosity played a vital role in how the crack occurred, which also directly affected the compressive strength of the concrete. Ref. [26] Normally, the crack path advances through aggregate, mortar, and ITZ, depending on the ability to handle the strength of each part as shown in Figure 11. In natural aggregate concrete (NCA), the crack path went through the mortar and ITZ around the aggregate. In contrast, in laboratory waste (L-RA) and building demolition waste aggregate concrete (B-CA), it was possible for some crack paths to go through the previously existing ITZ, which occurred between some of the previously existing mortar and aggregate, while other crack paths might go through the new ITZ, depending on which ITZ could bear higher strength. This result is explained by research from Li et al. [27] which found that old mortar is the weakest of Recycle Concrete Aggregate. If the parent strength of recycled aggregate is high, the ITZ might be able to handle more strength. Lastly, in precast slab waste aggregate (P-RA), due to high porosity in this type of aggregate, which resulted from the use of small-sized stones and in turn leading to a larger area of ITZ. Thus, the crack path could go through its ITZ much more easily compared to the other two.

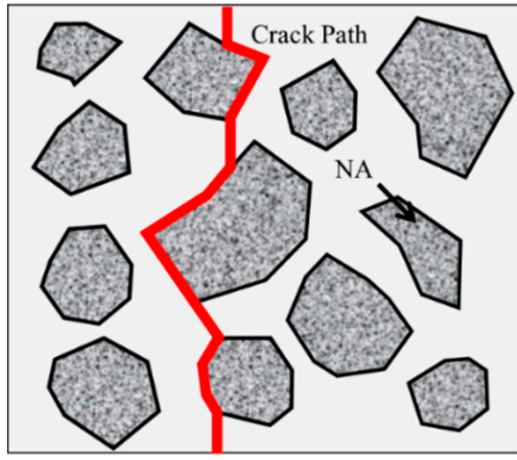

a) $\mathrm{NCA}$

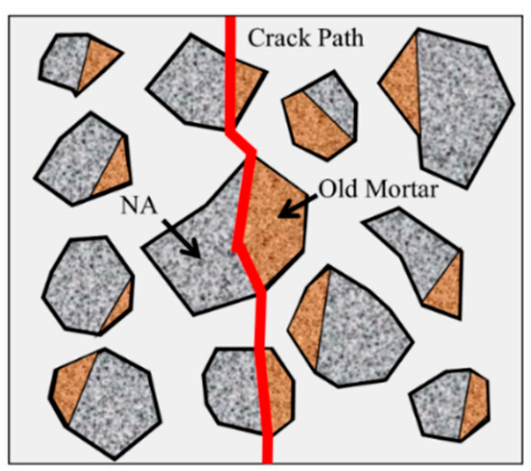

b) L-RA and B-RA

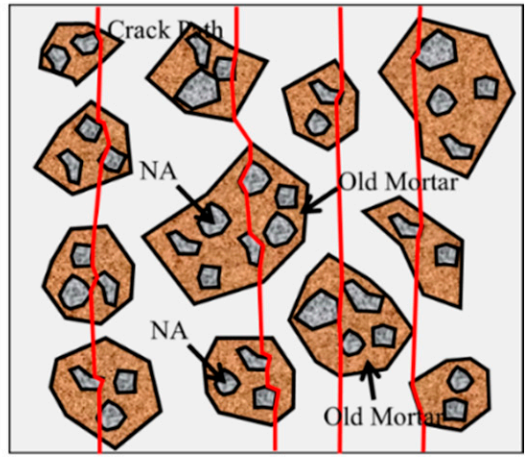

c) P-RA

Figure 11. Crack propagation in composition containing: (a) concrete containing NCA, (b) concrete containing L-RA and B-RA, and (c) concrete containing P-RA. 


\subsection{Durability Mode}

Photos from an image processing technique showed the area of each phase as shown in Figure 12. In the first row are raw photos which were denoised. The photos in the second row show the phase distribution in the cross-section area of the concrete after using an image processing technique. Finally, in the last row are the percentages of each phase of NCA, B-RA and P-RA. The phase of NCA and B-RA showed a similar distribution, unlike that of P-RA. To elaborate, the phase area of P-RA aggregate was nearly twice that of NCA and B-RA. The larger phase area of P-RA resulted in the increase in ITZ. The length of ITZ was determined by drawing a line in the CAD program as shown in Figure 13. Then, the area of ITZ of concrete cross-section was identified by multiplying the length of ITZ by its thickness $40 \mu \mathrm{m}$ on average based on the research by Zouaoui et al. [28] which proposed that the ITZ thickness ranged from 30-50 $\mu \mathrm{m}$.
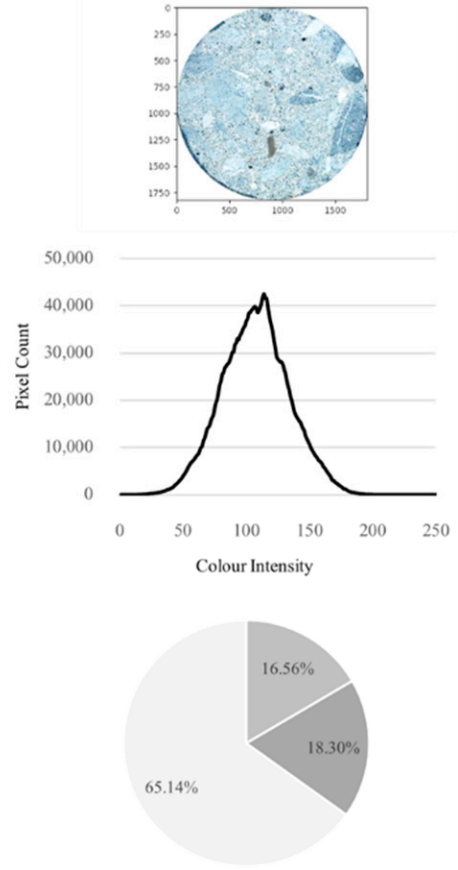

Mortar a Agregate Other

a.) NCA
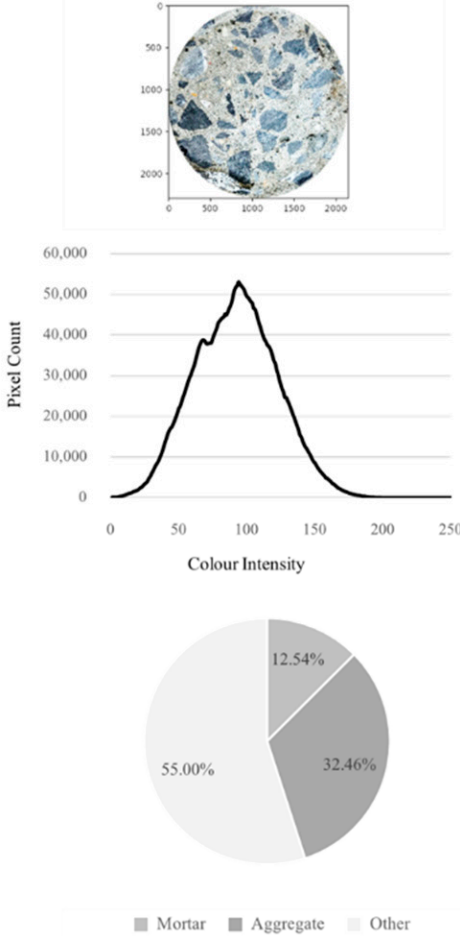

b.) B-RA
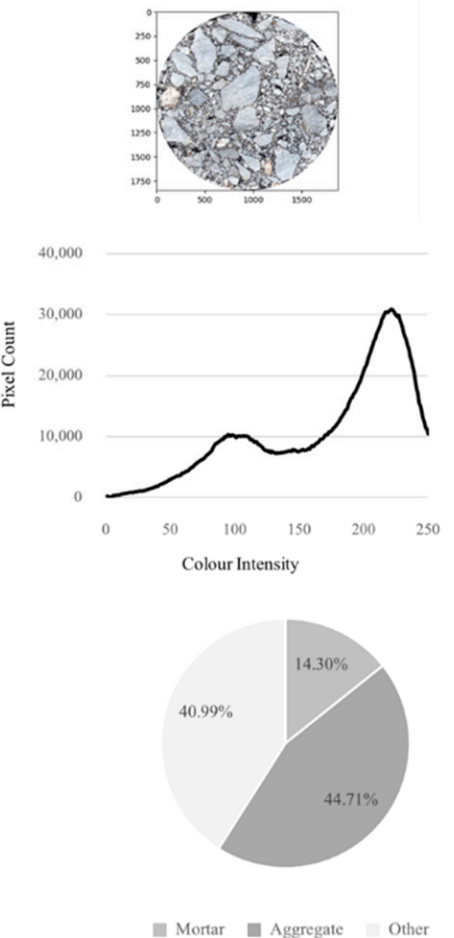

c.) P-RA

Figure 12. Phase distribution of (a) NCA and (b) B-RA and (c) P-RA using an image processing method from picture (top) to pixel distribution (middle) and pixel distribution (bottom).

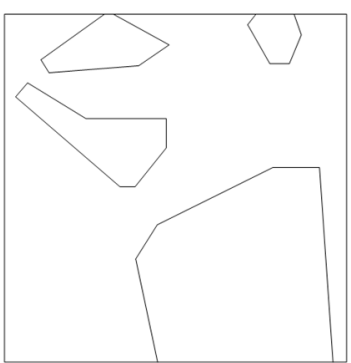

ITZ of NA

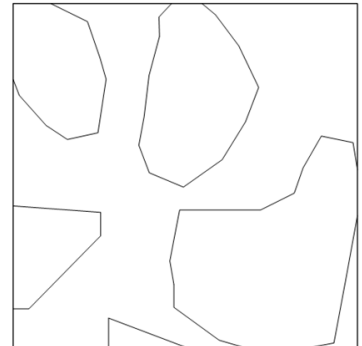

ITZ of B-RA

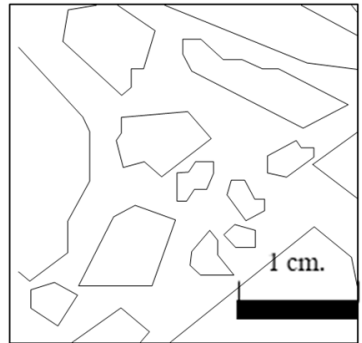

ITZ of P-RA

$2.43 \mathrm{~cm}$.

$3.60 \mathrm{~cm}$.

$23.51 \mathrm{~cm}$.

Figure 13. The length of Inter-Facial Transition Zone in concrete. 
Figure 14 demonstrates the schematic of chloride penetration through the cross-section of concrete. Chloride could penetrate the mortar to certain extent, but could penetrate the ITZ area better, while chloride could barely penetrate or could not penetrate the stone area at all. According to the research by Silva et al. which investigated the relationship between the total charge passed and chloride migration coefficient based on 120 studies, the relationship between these two is linear as presented in the equation below

$$
y=0.0034 x
$$

If

$$
\begin{gathered}
\mathrm{y}=\begin{array}{c}
\text { Chloride migration coefficient }(\mathrm{De}), \\
\mathrm{x}=\text { Total charge passed, }
\end{array} \\
\times 10-12 \mathrm{~m}^{2} / \mathrm{s} \\
\text { Coulombs }
\end{gathered}
$$

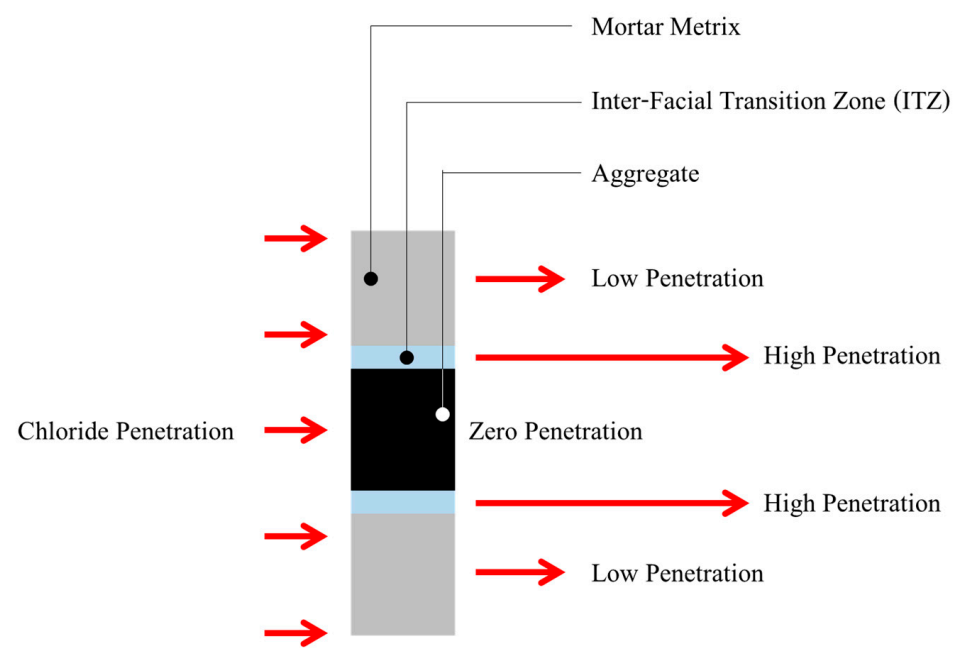

Figure 14. The schematic of chloride penetration through concrete.

The relationship between the ITZ area determined by the calculation above and the total charge passed was exponential. To illustrated, the area of ITZ obtained by an image processing technique played a crucial role in the amount of chloride penetration in exponential relationship which $\mathrm{R}^{2}=0.9994$ (Figure 15). This also directly affects the concrete durability in accordance with the research by Azarsa and Gupta [29].

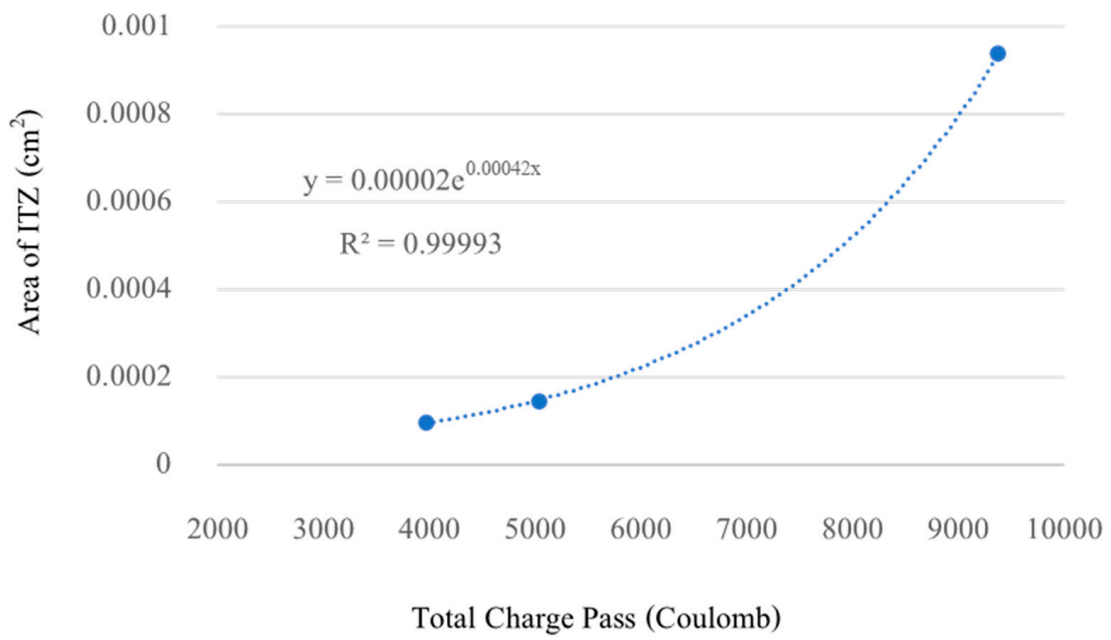

Figure 15. The relationship between the area of Inter-facial Transition Zone and the total charge passed. 


\section{Conclusions}

This research analyzed the chloride penetration behavior of natural aggregate concrete and that of recycled aggregate from three different sources. An image processing technique was used to explain the results which could be summarized as follows:

(a) Although the unit weight was similar to that of NA, the \% Water Absorption difference was 6-8 times more on average. In this respect, the pre-formed RCA concrete has been used from different sources, including from old buildings (B-RCA), from precast concrete slab specimens (P-RCA), and from laboratory test specimens (L-RCA) has lower chloride permeability properties than NA based concrete, but its penetration rate also depends on the shape of the aggregate which the aggregates are small and the quantity of old-adhered mortar. It will make the permeability a lot. Otherwise, the compressive strength was not significantly different between the ages of 7,14 and 28 days.

(b) Increasing of percent replacement is added, higher the compressive strength and chloride penetration resistance, the better from the Rapid Chloride Penetration Test at all 30\%, 60\% and 100\% Replacement Rations. It is worth noting that P-RCA has the highest chloride permeability. When considering the \% Water Absorption that P-RCA has the most and considering the mixed part of the aggregate which is somewhat more detailed than other types of aggregate, it can be determined that the chloride permeability properties and the strength is linked to the physical nature of the aggregates. In this experiment, the area of the ITZ was taken into account, which has a significant effect in the case of Recycle Aggregate concrete, since the aggregate is attached to the old ITZ from old-adhered Mortar.

(c) Using the Image Processing method for considering ITZ in this experiment, it was found that a highly consistent relationship between the size of the imaging ITZ area was identified and the amount of chloride permeation. An image processing technique could be used to explain the characteristics of each element in the cross-section of the concrete. The method yielded the results in accordance with the concrete behaviors. In the future, it would be possible to predict the properties of concrete if there are ample information archives of the cross-section of concrete.

Author Contributions: Conceptualization, W.Y.; methodology, W.Y.; software, K.N.; validation, W.Y. and K.N.; formal analysis, K.N.; investigation, K.N.; resources, K.N.; data curation, K.N.; writing-original draft preparation, K.N.; writing—review and editing, K.N.; visualization, K.N.; supervision, W.Y. project administration, K.N.; funding acquisition, K.N. All authors have read and agreed to the published version of the manuscript.

Funding: This research received no external funding.

Institutional Review Board Statement: Not applicable.

Informed Consent Statement: Not applicable.

Data Availability Statement: Not applicable.

Conflicts of Interest: The authors declare no conflict of interest.

\section{References}

1. Opon, J.; Henty, M. An indicator framework for quantifying the sustainability of concrete materials from the perspectives of global sustainable development. J. Clean. Prod. 2019, 218, 718-737. [CrossRef]

2. Dhir, R.K.; Dyer, T.D.; Newman, M.D. Ultimate Concrete Opportunities: Achieving Sustainability in Construction. In Proceedings of the International Conference on Global construction, London, UK, 5-6 July 2005.

3. Saez, P.V.; del Rio Merino, M.; Gonzalez, A.S.A.; Porras-Amores, C. Best Practice measure assessment for construction and demolition waste management in building constructions. Resour. Conserv. Recycl. 2013, 75, 52-62. [CrossRef]

4. Otsuki, N.; Miyasato, S.; Yodsudjai, W. Influence of Recycled Concrete on Interfacial Transition Zone, Strength, Chloride Penetration and Carbonation of Concrete. J. Mater. Civ. Eng. 2004, 15, 443-451. [CrossRef]

5. Rao, A.; Jha, K.N.; Misra, S. Use of Aggregate from Recycled Construction and Demolition Waste in Concrete. Resour. Conserv. Recycl. 2007, 50, 71-81. [CrossRef] 
6. Yu, Y.; Wang, P.; Yu, Z.; Yue, G.; Wang, L.; Guo, Y.; Li, Q. Study on the Effect of Recycled Coarse Aggregate on the Shrinkage Performance of Green Recycled Concrete. Sustainability 2021, 13, 13200. [CrossRef]

7. Malecot, Y.; Zingg, L.; Briffaut, M.; Baroth, J. Influence of free water on concrete triaxial behavior: The effect of porosity. Cem. Concr. Res. 2019, 120, 207-216. [CrossRef]

8. Accary, A.; Malecot, Y.; Daudeville, L. Design and Evaluation of a Deformable Sensor for Interstitial Pore Pressure Measurement in Concrete under Very High Stress Level. Appl. Sci. 2019, 9, 2610. [CrossRef]

9. Lu, B.; Shi, C.; Cao, Z.; Guo, M.; Zheng, J. Effect of carbonated coarse recycled concrete aggregate on the properties and mi-crostructure of recycled concrete. J. Clean. Prod. 2019, 233, 421-428. [CrossRef]

10. Kim, H.; Goulias, D.G. Shrinkage Behavior of Sustainable Concrete with Crushed Returned Concrete Aggregate. J. Mater. Civ. Eng. 2015, 27, 4014204. [CrossRef]

11. Knaack, A.M.; Kurama, C.Y. Behavior of Reinforced Concrete Beams with Recycled Concrete Coarse Aggregates. J. Struct. Eng. 2015, 141, B4014009. [CrossRef]

12. EN 1744-1; Tests for chemical properties of aggregates Chemical analysis. BSI: Pilsen, Czech Republic, 2012.

13. ASTM C33; Standard Specification for Concrete Aggregates. ASTM: West Conshohocken, PA, USA, 2016.

14. Vázquez, E.; Marilda Barra Bizinotto, M.B.; Aponte, D.; Jiménez, C. Improvement of the durability of concrete with recycled aggregates in chloride exposed environment. Constr. Build. Mater. 2014, 67,61-67. [CrossRef]

15. Nakhi, A.B.; Alhumoud, J.M. Effects of Recycled Aggregate on Concrete Mix and Exposure to Chloride. Adv. Mater. Sci. Eng. 2019, 2019, 7605098. [CrossRef]

16. Silva, R.V.; de Brito, J.; Neves, R.; Dhir, R.K. Prediction of Chloride Ion Penetration of Recycled Aggregate Concrete. Mater. Res. 2015, 18, 427-440. [CrossRef]

17. Mehta, P.K. Greening of the Concrete Industry for Sustainable Development. Concr. Int. 2002, 24, $23-28$.

18. Etxeberria, M.; Konoiko, M.; Garcia, C.; Perez, M.Á. Water-Washed Fine and Coarse Recycled Aggregates for Real Scale Concretes Production in Barcelona. Sustainability 2022, 14, 708. [CrossRef]

19. JIS A5002; Lightweight aggregates for structural concrete. JIS: Tokyo, Japan, 2003.

20. McNeil, K.; Kang, T. Recycled Concrete Aggregates: A Review. Int. J. Concr. Struct. Mater. 2012, 7, 61-69. [CrossRef]

21. Duan, Z.; Poon, C.S. Properties of recycled aggregate concrete made with recycled aggregates with different amounts of old adhered mortars. Mater. Des. 2014, 58, 19-29. [CrossRef]

22. Pedro, D.; de Brito, J.; Evangelista, L. Influence of the use of recycled concrete aggregates from different sources on structural concrete. Constr. Build. Mater. 2014, 71, 141-151. [CrossRef]

23. ACI 555; Concrete with Recycled Materials. ACI: Pflugerville, TX, USA, 2001.

24. ASTM C1202; Standard Test Method for Electrical Indication of Concrete's Ability to Resist Chloride Ion Penetration. ASTM: West Conshohocken, PA, USA, 2019.

25. ASTM C135; Standard Test Method for True Specific Gravity of Refractory Materials by Water Immersion. ASTM: West Conshohocken, PA, USA, 2015.

26. Yue, G.; Ma, Z.; Liu, M.; Liang, C.; Ba, G. Damage behavior of the multiple ITZs in recycled aggregate concrete subjected to aggressive ion environment. Constr. Build. Mater. 2020, 245, 118419. [CrossRef]

27. Li, W.; Xiao, J.; Sun, Z.; Shah, S. Failure processes of modeled recycled aggregate concrete under uniaxial compression. Cem. Concr. Compos. 2012, 34, 1149-1158. [CrossRef]

28. Azarsa, P.; Gupta, R. Electrical Resistivity of Concrete for Durability Evaluation: A Review. Adv. Mater. Sci. Eng. 2017, $2017,8453095$. [CrossRef]

29. Zouaoui, R.; Miled, K.; Limam, O.; Beddey, A. Analytical prediction of aggregates' effects on the ITZ volume fraction and Young's modulus of concrete. Int. J. Numer. Anal. Methods Geomech. 2017, 41, 976-993. [CrossRef] 